\title{
Assessment of climate change impact on wheat crop using MarkSim GCM in Varanasi, Uttar Pradesh
}

\section{PATEL ${ }^{* 1}$, A.K. NEMA ${ }^{1}$, R.S. SINGH ${ }^{2}$, M.K. YADAV ${ }^{2}$, K.K. SINGH ${ }^{3}$, S.K. SINGH ${ }^{4}$,P.K. RAI ${ }^{2}$ and S.M.SINGH ${ }^{2}$}

${ }^{I}$ Department of Farm Engineering, Institute of Agricultural Sciences, BHU, Varanasi-221005

${ }^{2}$ Department of Geophysics, Institute of Science, BHU, Varanasi-221005

${ }^{3}$ India Meteorological Department, New Delhi

${ }^{4}$ Department of Soil Science and Agricultural Chemistry, BHU, Varanasi-221005

*Corresponding author E-mail: chandrab263@gmail.com

\begin{abstract}
GFLD-CM3 model was used to generate weather data under RCPs scenario i.e. RCP 2.6, 4.5, 6.0 and 8.5 for years 2010, 2035, 2065 and 2095 for Varanasi, Uttar Pradesh. The generated data were used to assess the impact of climate change on phenology and yield of wheat crop using CERES-Wheat model. The results revealed that the impact climate change hastened reproductive stages (anthesis, maturity) and decreased yield in all scenarios. The impact was highest under RCP 8.5. Days to antheis and days to maturity were projected to reduce by 22 days and 24 days, respectively in 2095 whereas, grain yield decreased by 61.0 per cent.
\end{abstract}

Key words : MarkSim GCM, RCP, DSSAT-CERES, climate change and wheatcrop

Wheat (Triticum aestivum L.) is the second most important food grain crop of India.In Uttar Pradesh, it ranks first in respect of crop coverage area of 9.67 million ha with production of 33.66 million tons with an average productivity of is 3.41 tons ha"-1(Anon,2013-14; Singh et al. 2014).

The earth's climate is projected to undergo marked changes over the $21^{\text {st }}$ century due to natural processes and anthropogenic factors (IPCC, 2014). The climate change impacts on wheat production have broad and national repercussions on food security. Global circulation models and process-based crop models such as CERES-wheat have been used in different studies assessing the potential impacts of climate change on crop production. MarkSimDSSAT Weather File Generator, a software that not only downscales but also generates daily weather from general circulation models is used to overcome the coarse resolution of general circulation models (Jones and Thornton, 2013). The generated daily weather data characteristic of future climate scenarios was used to drive the CERES-wheat model.

\section{MATERIALS AND METHODS}

The daily weather data (solar radiation, rainfall, maximum and minimum temperatures) were generated from MarkSim DSSAT weather generator (http:// gisweb.ciat.cgiar.org/MarkSimGCM/) for Varanasi region from 2010-2095 (Jones and Thornton, 2013); average data of 99 replications of GFLD-CM3 model, with a spatial resolution of $1.2587 \times 2.5$ (latitude by longitude) was selected. Data were downloaded in DSSAT friendly format for RCP 2.6, 4.5, 6.0 and 8.5for 2010, 2035, 2065 and 2095. The generated weather data of year 2010 with RCP 2.6, 4.5, 6.0 and 8.5 were chosen as baseline for assessment of climate change impact in future years $(2035,2065$ and 2095).

The CERES-wheat model embedded in DSSATv4.6 (Hoogenboom et al., 2015) was used to assess climate change impact on yields of wheat crop of Varanasi district of Uttar Pradesh state, India. The corresponding daily weather and soil data $\left(25^{\circ} 182\right.$ north latitude, $83^{\circ} 102$ east longitude and 76 meter above mean sea level) were collected from Agriculture Research Farm, Banaras Hindu University (BHU), Varanasi. Calibrated and validated genetic coefficients for cultivar HUW 510 by Patel et al. (2017) has been adopted for simulation.

\section{RESULTS AND DISCUSSION}

\section{Climate change and variability at Varanasi}

For assessment of climate change and variability, 30 years (1981 to 2010) weather data of Varanasi was analyzed and projected for years i.e. 2010, 2035, 2065 and 2095 (Table 1). The maximum temperature was found to increase 
Table 1:Projected climatology using observed weather data of Varanasi district for future years

\begin{tabular}{lrrrr}
\hline Weather parameters & 2010 & 2035 & 2065 & 2095 \\
\hline Maximum temp. $\left({ }^{\circ} \mathrm{C}\right)$ & $(+) 0.5$ & $(+) 0.9$ & $(+) 1.4$ & $(+) 1.9$ \\
Minimum temp. $\left({ }^{\circ} \mathrm{C}\right)$ & $(+) 0.5$ & $(+) 1.0$ & $(+) 1.5$ & $(+) 2.0$ \\
Solar radiation $\left(\mathrm{MJm}^{-2} \mathrm{day}^{-1}\right)$ & $(-) 1.4$ & $(-) 2.6$ & $(-) 4.1$ & $(-) 5.5$ \\
Rainfall $(\mathrm{mm})$ & $(-) 141.5$ & $(-) 259.5$ & $(-) 401.0$ & $(-) 542.5$ \\
\hline
\end{tabular}
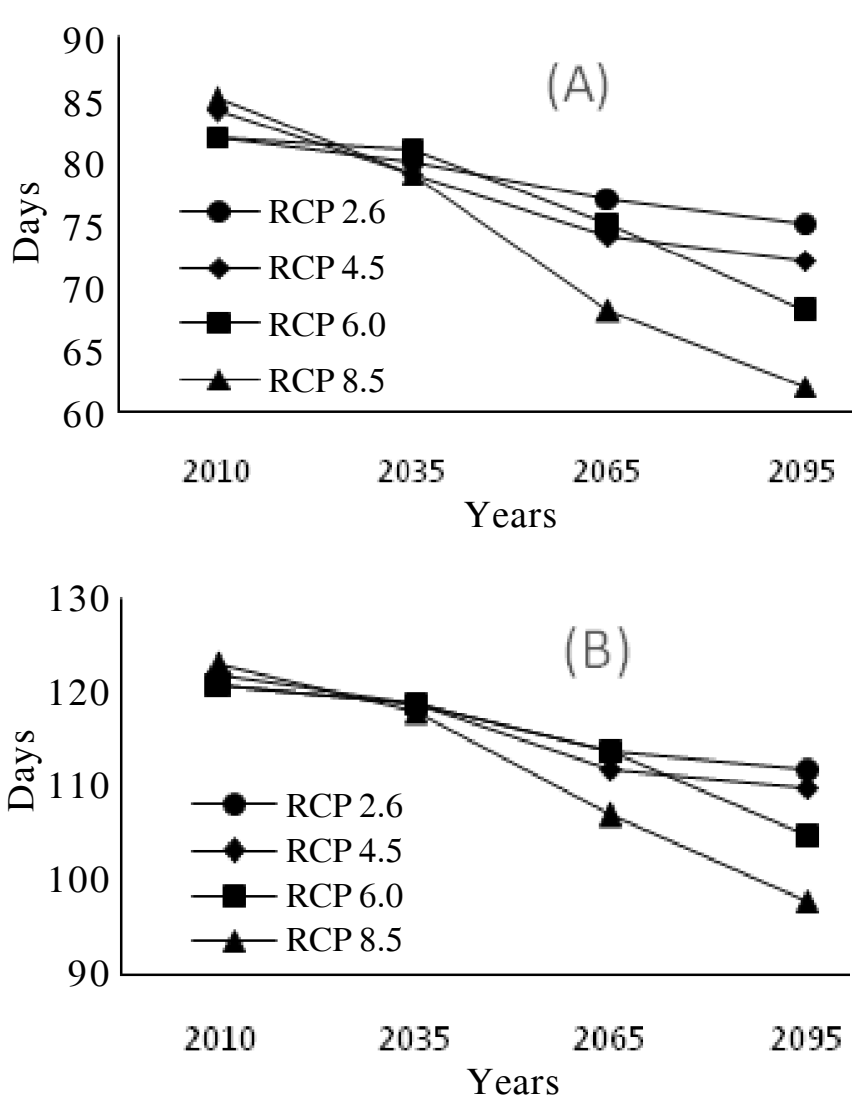

Fig. 1: Impact of climate change on (A) days to anthesis and (B) days to maturity

from $0.5^{\circ} \mathrm{C}$ to $1.9^{\circ} \mathrm{C}$, whereas, minimum temperature increased from 0.5 to $2.0^{\circ} \mathrm{C}$ for projected years 2010 to 2095 . Solar radiation and rainfall were projected to decrease from 1.4 to $5.5 \mathrm{MJm}^{-2} \mathrm{day}^{-1}$ and from 141.5 to $542 \mathrm{~mm}$, respectively.

\section{Impact of climate change on phenology of wheat crop}

The days to anthesis and days to maturity simulated by the CERES-Wheat model under different RCP scenario in different years 2010,2035, 2065 and 2095 presented in Fig. 1 revealed that the duration would be shorten under all scenarios (RCP 2.6, 4.5, 6.0 and 8.5) and also with years. Upto 2035, there is not much difference, but there after sharp decline in duration of both days to anthesis and maturity is observed under RCP 6.0 and RCP 8.5. The highest decrease was under RCP 8.5 in 2095.In all scenarios,

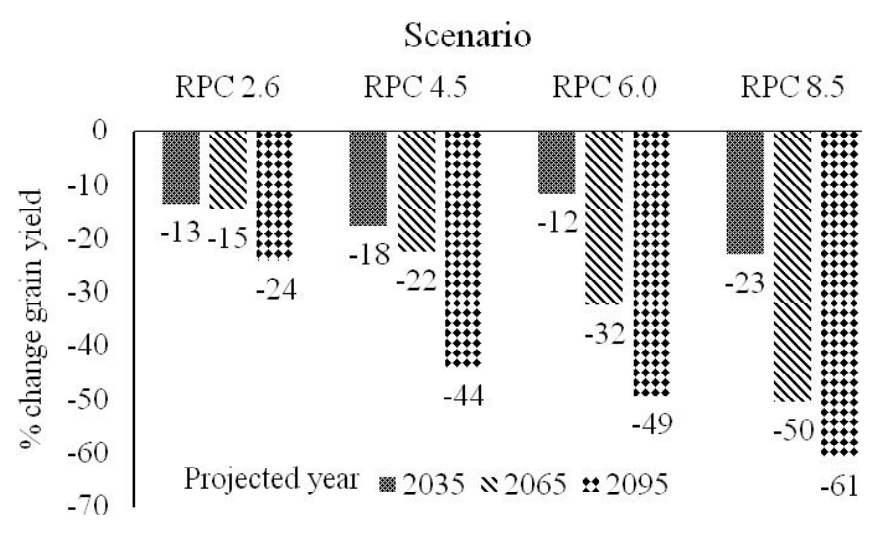

Fig.2: Change in grain yield of wheat under different RCPs for year 2035, 2065 and 2095 as compared to that for year 2010

increased maximum and minimum temperature hastening on anthesis and maturity, thereby decreasing the length of the life cycle which shorten the reproductive period resulting in lower grain yield (Menzel et al., 2006).

\section{Impact of climate change on wheat yield}

Changes in grain yield of wheat were evaluated by comparing the future wheat yields to the baseline yields of projected year of 2010 with its scenario, and then by stating the change. The effect of climate change on wheat production were studied for projected years i.e. 2035, 2065 and 2095, under climate RCP 2.6, 4.5, 6.0 and 8.5 and were compared with that simulated for 2010 . The maximum yield decrease was observed in the scenario RCP 8.5, which ranged from -23 to -61 per cent. These results show RCP 8.5 as the most resilient scenario and RCP 2.6 as least resilient scenario to climate change. Projected year 2035 was the least vulnerable and on 2095 the most vulnerable under the all emission scenario (Welikhe et al.,2016). Yadav et al.,(2015) also reported decrease in wheat grain yield with increase in temperature.

\section{CONCLUSIONS}

It can be concluded that climate change could potentially result not only in shortening the duration of wheat crop but also in decreasing wheat yields in Varanasi 
region. Maximum grain yields were projected to decrease under RCP 8.5 in all years with extreme being observed at the end of the century.

\section{AKNOWELDEMENT}

We are thankful to Ministry of Earth Science and India Meteorological Department, Govt. of India, New Delhi for providing the financial and technical assistance toconduct the present investigation in the form of fellowship and "Field Experiment" budget under FASAL project.

\section{REFERENCES}

Anonymous (2013-14). Directorate of Economicsand Statistics, Department of Agriculture and Cooperation.

Hoogenboom, G., J.W. Jones, P.W. Wilkens, C.H. Porter, K.J. Boote, L.A. Hunt, U. Singh, J.I. Lizaso, J.W. White, O. Uryasev, R. Ogoshi, J. Koo, V. Shelia and G.Y. Tsuji. (2015). Decision Support System for Agrotechnology Transfer(DSSAT) Version v4.6(http://dssat.net). DSSAT Foundation, Prosser, Washington.

IPCC (2014). Summary for Policy Makers. Climate Change 2014: Impacts, Adaptation and VulnerabilityContributions of the Working GroupII to the Fifth Assessment Report.

Jones, P.G. and P.K. Thornton. (2013). Generating Downscaled Weather Data from a Suite of Climate Models for
Agricultural Modelling Applications. Agric. Systems, 114:1-5.

Menzel, A., Sparks, T. H., Estrella, N., Koch, E., Aasa, A., Ahas, R. and Zust, A. (2006). European phenological response to climate change matches the warming pattern. Global Change Biol., 12(10): 1969-1976.

Patel, C., Nema,A.K., Singh, R.S., Yadav, M.K., Singh, S.K., and Singh, S.M. (2017)Evaluation ofDSSAT-CERES model for irrigation scheduling of wheat crop in Varanasi region of Uttar Pradesh. J. Agrometeorol., 19 (2):120124.

Singh, R.S., Patel, C., Yadav, M.K. and Singh, M.K. (2014). Yield forecasting of rice and wheat crops for eastern Uttar Pradesh. J. Agrometeorol., 16(2):199-202.

Welikhe, Pauline; Essamuah-Quansah, Joseph; Boote, Kenneth; Asseng, Senthold; ElAfandi, Gamal; Fall, Souleymane; Mortley,Desmond; andAnkumah, Ramble(2016) “Impact of Climate Change on Corn Yields in Alabama," Prof. Agric. Workers J., :Vol. 4: No. 1, 12.

Yadav, M.K., Singh, R.S., Singh, K.K., Mall, R.K., Patel, C.B., Yadav, S.K. and Singh, M.K. (2015). Assessment of climate change impact on productivity of different cereal crops in Varanasi, India. J. Agrometeorol., 17(2):179184. 